\title{
A quantitative occupational risk assessment methodology based on TOPSIS- Sort with its application in aluminum extrusion industry
}

\author{
Muhammet Gül \\ Munzur University, Faculty of Health Sciences, Department of Emergency Aid and Disaster Management, Tunceli, \\ Turkey \\ muhammetgul@munzur.edu.tr@ \\ Received date: 27.05.2021, Accepted date: 06.06 .2021
}

\begin{abstract}
The metal products industry, including the aluminum extrusion industry, is one of the sectors with high risk in terms of occupational health and safety (OHS). Considering this fact and the increasing trend of occupational accidents in the sector, the need to enhance occupational safety becomes clear. Therefore, this study proposes a quantitative occupational risk assessment by a sorting-based technique for order performance by similarity to ideal solution (TOPSIS-Sort) methodology to manage risks in the aluminum extrusion industry. A sorting-based methodology is proposed since the necessity of making a risk classification according to the obtained risk value, which is an important process in risk assessment. The methodology has been demonstrated by evaluating 28 potential hazards under three risk parameters (probability, severity and frequency). The assessed hazards are divided into five risk clusters (Very high risk, High risk, Substantial risk, Possible risk, and Risk) and control measures that will initiate the reduction of risks have been determined. Results of the study show that while one hazard has been placed in the Very high risk cluster, 3 in the High risk cluster, 23 in the Substantial risk cluster and one in the Possible risk cluster.
\end{abstract}

Keywords: aluminum extrusion, quantitative occupational risk assessment, TOPSIS-Sort

\section{TOPSIS-Sort temelli nicel bir mesleki risk değerlendirme metodolojisi ve alüminyum ekstrüzyon endüstrisinde uygulanması}

\section{$\ddot{\mathbf{O} z}$}

Alüminyum ekstrüzyon üretimini de kapsayan metal ürünleri sektörü, iş sağlığı ve güvenliği (İSG) açısından yüksek risk taşıyan sektörlerden biridir. Bu durum ve sektördeki iş kazalarının artış eğilimi göz önüne alındığında, iş güvenliğinin artırılması ihtiyacı ortaya çıkmaktadır. Bu nedenle, bu çalışma, alüminyum ekstrüzyon endüstrisindeki riskleri yönetmek için kümeleme temelli bir TOPSIS yaklaşımı (TOPSIS-Sort) ile nicel bir mesleki risk değerlendirmesi önermektedir. Risk değerlendirmesinde önemli bir süreç olan elde edilen risk değerine göre risk sınıflandırmasının gerekliliği nedeniyle sıralamaya dayalı bir metodoloji önerilmiş̧ir. Metodolojinin uygulanabilirliği, 28 potansiyel tehlikenin üç risk parametresi (olasılık, ciddiyet ve sıklık) altında değerlendirilmesiyle gösterilmiştir. Değerlendirilen tehlikeler beş risk kümesine (Çok yüksek risk, Yüksek risk, Önemli risk, Olası risk ve Risk) bölünmüş ve risklerin azaltılmasını sağlayacak kontrol önlemleri belirlenmiştir. Çalışmanın sonuçları, Çok yüksek risk kümesine bir tehlikenin, Yüksek risk kümesine 3, Önemli risk kümesine 23 ve Olası risk kümesine bir tehlike atandığını göstermektedir.

Anahtar Kelimeler: Alüminyum ekstrüzyon, nicel işs sağlığı risk değerlendirmesi, TOPSIS-Sort

\section{INTRODUCTION}

The demand for aluminum worldwide has increased significantly in the last decade (Demirci, 2013). As a result of the increase in production on demand and the increased competition on the market, the strategies of global and local players have been the most important factor determining the market, from extraction as raw materials to their transformation into final products. Aluminum extrusion has been used as an important production method for many years. This method can be defined as obtaining a product (pipe, bar, profile) that is quite long in its cross-section by pressing aluminum through a mold (Saha, 2000). In this method, a metal wedge is placed in a receiver sleeve, and a metal 
wedge is pressed by means of a stamp. Metal wedge is forced through a mold called matrix. Thus, production is realized by the extrusion method. There are two types of extrusion that are named as direct extrusion and indirect extrusion. To understand the trend in the aluminum production market more easily, it is necessary to look and evaluate each link of the value chain from a different perspective. The aluminum value chain includes two important links, primary and secondary. The first is bauxite which is the ore. Secondary aluminum is obtained from scrap products. According to the production methods, aluminum products are grouped as raw materials (ingots, billets) and semi-products (intermediate goods), extrusion products (aluminum profiles, bars, sheets, wire rods), flat products (plate, strip, foil), cast products and conductors. Turkey is a country whose production rate is increasing, especially in extrusion and flat products (Demirci, 2013). Along with the sector's growth, a number of occupational hazards have emerged that need to be taken into account. In order to protect employees in Turkey from hazards and associated risks, risk assessment has been made mandatory by law. According to OHS Law No. 6331, the employer is responsible for determining the OHS measures to be taken as a result of the risk assessment and providing the required personal protective equipment. In addition, it should be ensured that the necessary controls and measurements are carried out to determine the risks that employees are exposed to in the worksite environment in terms of OHS. OHS measures to be applied in the workplace, working methods and production methods should increase the level of protection of employees in terms of health and safety and be applicable at all levels of the administrative structure of the workplace. In this context, it becomes necessary to carry out a fullfledged risk assessment study to reverse the trend in occupational accidents and protect employees from the destructive consequences of the workplace, process, environment, and human-based hazards.

Many scholars have handled the OHS risk assessment issues in the aluminum industry via MCDM-based methods (Marhavilas and Koulouriotis, 2008; Aneziris et al. 2010; Gul and Guneri, 2016; Gul and Guneri, 2018). Marhavilas and Koulouriotis (2008) proposed a quantitative risk assessment technique, including the proportional and the decision matrix technique, and applied them to an aluminum extrusion industry's worksite in Greece.
Aneziris et al. (2010) studied occupational risk assessment in an aluminum plant in Northern Greece by a new risk model. Their model hierarchically evaluates occupational risks (e.g., at hazard level, activity level, job level and overall company risk level). Then, in more recent literature, Gul and Guneri (2016) benefitted from multi-criteria decisionmaking models in occupational risk assessment of the aluminum industry. Their first study jointly used fuzzy Analytic Hierarchy Process (FAHP) and fuzzy TOPSIS under the decision matrix risk-assessment technique, a two-dimensioned risk model. They assigned weights of the risk parameters "likelihood and severity" by fuzzy AHP. Then they determined orders of priority of 23 various hazard groups by using fuzzy TOPSIS. In their second study, similar to their first study, they jointly used fuzzy AHP, and fuzzy TOPSIS under a classical risk analysis concept called proportional risk assessment. They performed a case study in the facility of a leading aluminum extrusion manufacture in Turkey. Unlike MCDM, some scholars propose models for a specific alumnum industry processes such as (Bi et al. 2021; Sanjari et al. 2021). While $\mathrm{Bi}$ et al. (2021) handle risk assessment of aluminum dust explosion for polishing process based on laboratory tests, Sanjari et al. (2021) evaluate the health risks resulting from occupational exposure to chemicals in an aluminum rolling mill to propose effective control measures.

When each of the abovementioned limited numbers of OHS risk assessment studies conducted in the aluminum industry are examined, it is seen that the suggested methods offer a solution in terms of expressing the risk with a numerical value. However, another important process in risk assessment is the necessity of classifying the obtained risk value (risk score) depending on the risk values of each risk in the list. This will help in responding to the questions of what kind of precautions the decision-makers should take against the quantified risk and what kind of priority should be assigned to each one. Therefore, to remedy the gap and contribute to the literature in this regard, a sorting-based TOPSIS methodology is applied to manage risks in the aluminum extrusion industry. Since the TOPSIS and its variants are frequently applied to the OHS risk assessment problems due to its ease to use and having a structure focused on proximity to the ideal solution ( $\mathrm{Gul}$, 2018), we used its extended version in an OHS risk assessment problem in this paper. Moreover, the use 
of MCDM methods in an OHS risk assessment problem for sorting purposes also seems to contribute to the literature on its own.

\section{MATERIAL AND METHODS}

TOPSIS multi-criteria decision-making method has been initially proposed by Hwang and Yoon (1981). It is used to select the best alternative from a number of homogeneous alternatives under a certain number of decision criteria. TOPSIS, takes into account the shortest distance of the best alternative to the positive-ideal solution as well as the farthest distance to the negative ideal solution. Due to the variety and prevalence of the application area, many extensions have been proposed on the first proposed TOPSIS version and successfully hybridized with other MCDM methods (Behzadian et al. 2012).

There are three main goals in an MCDM problem (Roy, 1990; Vanderpooten, 1990; Vincke, 1992; Yoon \& Hwang, 1995): (1) Choice, (2) Classification/Sorting, and (3) Ranking. Sorting problems fall under a group of methods known as classification problems. This problem is concerned with assigning a number of alternatives to a homogeneous class. Various MCDM methods have been proposed to address sorting problems (AHPSort, VIKOR-Sort, DEA-Sort, etc.) (Ishizaka et al. 2012; Ishizaka et al. 2018; Krejčí and Ishizaka, 2018; Demir et al. 2018; Ishizaka and López, 2019; Xu et al. 2019; Labella et al. 2021; Qin et al. 2021). Apart from the above-mentioned MCDM sorting methods, TOPSIS-Sort is initially proposed by Sabokbar et al. (2016). Then it is used by some scholars and applied to various problems (de Lima Silva and de Almeida Filho, 2020; Yamagishi and Ocampo, 2021). This study demonstrates the use of the TOPSIS-Sort approach for occupational health and safety risk assessment.

The components of the decision problem and procedural steps are as follows:

$h$ refers to alternatives ("hazards" in our problem) and $(i=1,2, \ldots, h) . r$ refers to the decision criteria ("risk parameters" in our problem) and $(j=1,2, \ldots, r) . c$ refers to the clusters and $(k=1,2, \ldots, c)$.

Step 1: Determine the risk parameters for the assessment of hazards in risk assessment. In many classical risk assessment concepts, these parameters are either two (for example, the matrix method has two parameters called severity and probability) or three (for example, in Fine-Kinney there are three parameters: severity, probability and frequency; in FMEA there are three parameters: severity, probability and detectability.). A detailed explanation of the risk parameters considered in this study will be given in the "results and discussion" section.

Step 2: Provide the hazard list of the workplace. This list includes the names of the hazards likely to occur in all indoor and outdoor areas of the workplace, the definition of the risks that will arise as a result of these hazards, and who will be affected by the emergence of hazards (employees, environment, etc.).

\section{Step 3: Determine the weights of risk parameters.} Priority weight $\left(w_{j}\right)$ indicates the level of importance determined for each risk parameter. It is a value ranging from $0-1$. There are a number of subjective and objective methods in the literature to calculate this. Expert judgment, survey and analytical methods including MCDM are examples. In determining the priority weights of risk parameters, MCDM methods such as Analytical Hierarchy Process (Saaty, 1980), Analytical Network Process (Saaty, 1984), Entropy (Shannon, 1948; Zou et al., 2006), Best-Worst Method (Rezaei, 2015) can be used.

Step 4: Construct a decision matrix. The decision matrix $X^{e}=\left(x_{i j}^{e}\right)_{h x r}$ represents the performance score (evaluation score) of the $i$ th hazard $(i=$ $1,2, \ldots, h)$ on the $j$ th risk parameter $(j=1,2, \ldots, r)$ rated by the expert (decision-maker) $e=1,2, \ldots, E$. Here, the selection of the scale to be used while constructing the decision matrix is also an important issue. Details about the scale to be used in this study will be given in the case study section.

Step 5: Define the set of limit profiles. It is denoted as $P=\left\{\left(p_{l}^{1}, p_{u}^{1}\right),\left(p_{l}^{2}, p_{u}^{2}\right), \ldots,\left(p_{l}^{k}, p_{u}^{k}\right)\right\} \quad$ where $\left(p_{l}^{1}, p_{u}^{1}\right),\left(p_{l}^{2}, p_{u}^{2}\right)$ and $\left(p_{l}^{k}, p_{u}^{k}\right)$ are the limit profiles of clusters $c_{1}, c_{2}$ and $c_{k}$ respectively. The upper and lower limits of cluster $k=1,2, \ldots, c$ are denoted as $p_{u}^{k}$ and $p_{l}^{k}$. It should be noted that $p_{l}^{k}=p_{u}^{k-1}$. Experts or decision-maker group provide these limit profiles in the context of the evaluation scale.

Step 6: Construct aggregated decision matrix. By using a weighted mean aggregation operator, the 
decision matrix $X^{e}=\left(x_{i j}^{e}\right)_{h x r}$ is transformed into $\left(x_{i j}\right)_{h x r}$. Here $x_{i j}=\frac{1}{E} \sum_{e=1}^{E} x_{i j}^{e}$. When the profile values are added to the aggregated decision matrix, it is denoted as $\Lambda=(X, P)=\left(\lambda_{i j}\right)_{h^{\prime} x r}$. Here, $h^{\prime}=h+$ c.

Step 7: Normalize $\Lambda$. Using the Eq. (1) below, the $\Lambda$ is normalized as $N=\left(\varepsilon_{i j}\right)_{h^{\prime} x r}$.

$\varepsilon_{i j}=\left(\left(\frac{\lambda_{i j}}{\max _{i j} \lambda_{i j}} \mid j \in R_{\text {benefit }}\right),\left(1-\frac{\lambda_{i j}}{\operatorname{mij}_{i j} \lambda_{i j}} \mid j \in R_{\text {cost }}\right)\right)$

Here, while $R_{\text {benefit }}$ refers to the set of 'maximizing' risk parameters and $R_{\text {cost }}$ means the set of 'minimizing' risk parameters, respectively.

Step 8: Compute the normalized decision matrix. $S=\left(s_{i j}\right)_{h^{\prime} x r}$ refers to the normalized decision matrix and is calculated via Eq. (2).

$s_{i j}=\frac{\varepsilon_{i j}}{\sqrt{\sum_{i=1}^{h^{\prime}} \varepsilon_{i j}^{2}}} \forall i, j$

Step 9: Compute the weighted normalized decision matrix. $V=\left(v_{i j}\right)_{h^{\prime} x r}$ refers to the normalized decision matrix and is calculated via Eq. (3).

$v_{i j}=s_{i j} \times w_{j}$

Step 10: Determine positive ideal and negative ideal solutions. $A^{+}$and $A^{-}$denote the positive ideal and negative ideal solutions and are calculated as in Eqs. (4-5).

$A^{+}=\left\{\left(\max _{j} v_{i j} \mid j \in R_{\text {benefit }}\right),\left(\min _{j} v_{i j} \mid j \in R_{\text {cost }}\right)\right\}=$ $\left\{v_{j}^{+} \mid j=1,2, \ldots, r\right\}$

$A^{-}=\left\{\left(\min _{j} v_{i j} \mid j \epsilon R_{\text {benefit }}\right),\left(\max _{j} v_{i j} \mid j \in R_{\text {cost }}\right)\right\}=$ $\left\{v_{j}^{-} \mid j=1,2, \ldots, r\right\}$

Step 11: Compute distance from positive \& negative ideal solution. By using an m-dimensional Euclidean distance measure, the distances of each hazard from the positive-ideal solution $\left(\right.$ Dist $\left._{i}^{+}\right)$and the negative-ideal solution $\left(\right.$ Dist $\left._{i}^{-}\right)$are computed as in Eqs. (6-7).
$D i s t_{i}^{+}=\sqrt{\sum_{j=1}^{h^{\prime}}\left(v_{i j}-v_{j}^{+}\right)^{2}} \forall i$

$\operatorname{Dist}_{i}^{-}=\sqrt{\sum_{j=1}^{h^{\prime}}\left(v_{i j}-v_{j}^{-}\right)^{2}} \forall i$

Step 12: Obtain closeness coefficient $(\mathrm{CC})$ value of TOPSIS for each hazard. Using Eq. (8), $C C_{i}$ of each hazard is calculated.

$C C_{i}=\frac{\text { Dist }_{i}^{-}}{\text {Dist }_{i}^{+}+\text {Dist }_{i}^{-}} \forall i$

Step 13: Obtain the deviation of the upper and lower limit profiles of the cluster $\boldsymbol{k}$ from the ideal solution. The values of $C C_{j} p_{u}^{k}$ and $C C_{j} p_{l}^{k}$ denote the deviation of the upper limit profile of the cluster $k$ from the ideal solution and the deviation of the lower limit profile of the cluster $k$ from the ideal solution, respectively. We compare $C C_{i}$ with $C C_{j} p_{u}^{k}$ and $C C_{j} p_{l}^{k}$ using the Eq. (9).

$C C_{j}{ }_{l}^{k}<C C_{i}<C C_{j} p_{u}^{k} \forall i, k$

The hazards with $C C_{i}>C C_{j} p_{l}^{k}$ and $C C_{i}<C C_{j} p_{u}^{k}$ are assigned to cluster $k$. In this step, all hazards are assigned to their suitable clusters.

\section{RESULTS AND DISCUSSION}

In this section, a step-by-step presentation of the application of the methodology detailed above in a facility operating in the aluminum extrusion industry has been carried out.

Step 1: Three risk parameters are considered as probability, severity, and frequency. A risk value (risk score) is calculated as a combination of these three parameters in a traditional risk analysis context. Marhavilas and Koulouriotis (2008) calculated the risk by giving a value between 1 and 10 to each parameter. Probability is defined as the likelihood of an accident or damage when the hazard occurs. Severity means the most probable result of a potential undesirable accident event, including injuries and property damages. Frequency corresponds for the exposure. It refers to the frequency of occurrence of the hazard event (Gul et al. 2021).

Step 2: Within the scope of this study, 28 hazards are evaluated. The activity areas where the hazards are emerged in the factory and their detailed descriptions are presented in Table 1. 
Table 1. Hazard list

\begin{tabular}{|c|c|c|}
\hline ID & Specific activity area & Hazard description \\
\hline H1 & Overhead cranes & Fall of material \\
\hline $\mathrm{H} 2$ & Electric board, fuse & Lack of annual periodic measurement of grounding, re-checking of internal electrical installation, panels \\
\hline $\mathrm{H} 3$ & Movable machines \& machines with rotating parts & The moving and rotating parts of the machines are without protection \\
\hline $\mathrm{H} 4$ & Movable machines \& machines with rotating parts & The inappropriateness of the moving and rotating parts of the machines \\
\hline H5 & Messy stacking & Possibility of messy stacking of materials, falling from a height \\
\hline H6 & Press & Possible negativities in the extrusion process \\
\hline $\mathrm{H} 7$ & Working with the compressor & Deficiencies regarding written instructions on compressor usage and periodic maintenance \\
\hline $\mathrm{H} 8$ & Tubes & Tipping of the tubes, lack of usage and storage conditions \\
\hline H9 & Cutting of aluminum billets & Negativities to be experienced in profile cutting \\
\hline H10 & Annealing and entering the billets into the mold & Negativities to be experienced in the molding process \\
\hline H11 & Electric panels & Be open of electric panel covers \\
\hline H12 & Electric panels & Hazards due to safety signs and residual current relay causes \\
\hline H13 & Surface coating processes & Problems to be encountered during the chemical surface coating process \\
\hline H14 & Chemicals & The compatibility of the chemicals used \\
\hline H15 & Painting & Using appropriate personal protective equipment (PPE) in the painting process \\
\hline H16 & Drying & Falling of hanged profiles \\
\hline H17 & Storage of oxygen cylinders & Storage of oil barrels near oxygen cylinders \\
\hline H18 & Powder & Failure to take adequate security measures against dust \\
\hline H19 & Training of employees & Employees' failure to receive appropriate vocational training for their job \\
\hline $\mathrm{H} 20$ & Training of employees & Employees not receiving basic OHS training \\
\hline $\mathrm{H} 21$ & Profile wrapping, packaging & Fall of material \\
\hline $\mathrm{H} 22$ & Risk analysis & Continue to work in cases where the risk analysis needs to be renewed and updated \\
\hline $\mathrm{H} 23$ & Electrical installation & Inability to reach the panels as a result of placing materials in front of the electrical panels \\
\hline $\mathrm{H} 24$ & Workplace disorder & Possibility of uneven stacking of materials, leaving them untidy and falling from height \\
\hline $\mathrm{H} 25$ & Changing cabinets & Discomfort that may occur due to the lack of hygiene conditions in the changing areas \\
\hline $\mathrm{H} 26$ & Messy stacking & Poor stacking, untidiness, Mess \\
\hline $\mathrm{H} 27$ & Use of personal protective equipment & Not using personal protective equipment \\
\hline $\mathrm{H} 28$ & Aluminum shavings & The sinking of aluminum shavings, respiratory illness \\
\hline
\end{tabular}

Step 3: Priority weight $\left(w_{j}\right)$ vector for the three risk parameters are determined by Best-Worst Method (BWM). This is a recently suggested pair wise comparison-based MCDM method (Rezaei, 2015). It requires a lower number of comparisons compared to AHP. Also, it provides a more consistent evaluation on the judgments of experts. For this reason, we used BWM to determine the importance weights of probability, severity and frequency parameters. By using Saaty's 1-9 scale, best-to-others and other-to-worst vectors of the evaluators (OHS experts from the facility make this evaluation in a group consensus), weights of parameters are obtained as shown in Figure 1.

Step 4: The OHS experts in the observed aluminum extrusion production facility rated the hazards with respect to three risk parameters using the scales of each parameter given in Figure 2 and obtained a decision matrix. The scales for each parameter can be reached in the reference of Marhavilas and Koulouriotis (2008). While the highest value (the grade of 10) of probability parameter refers to "Unavoidable" for the probability of an undesirable event, the lowest value (the grade of 1) indicates a meaning of "Impossible" linguistically. On the other hand, the highest and lowest values of severity parameter express "Death" and "No one human injury", respectively. The full descriptions of the scales for each parameter is also provided in Figure 2.

Step 5: In our case study, we have determined five clusters as "Risk, Possible risk, Substantial risk, High risk, Very high risk". Therefore, $P=$ $\{(0,2),(2,3),(3,5),(5,7),(7,10)\} . \quad c_{1} \triangleq(0,2), c_{2} \triangleq$ $(2,3), c_{3} \triangleq(3,5), c_{4} \triangleq(5,7), c_{5} \triangleq(7,10)$ are the limit profiles of clusters. These are determined by the OHS expert team as stated in Step 3.

Step 6: The aggregated decision matrix with limit profiles is structured in this step. It is demonstrated in Table 2. These are the average of OHS experts' ratings on each hazard with respect to three risk parameters. 


\begin{tabular}{|c|c|c|c|c|}
\hline Criteria Number $=3$ & Criterion 1 & Criterion 2 & Criterion 3 & \\
\hline Names of Criteria & Probability & Severity & Frequency & \\
\hline Select the Best & Severity & & & \\
\hline Select the Worst & Frequency & & & \\
\hline Best to Others & Probability & Severity & Frequency & \\
\hline Severity & 2 & 1 & 3 & 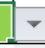 \\
\hline & & & \multirow{6}{*}{\begin{tabular}{|l|}
2 \\
3 \\
4 \\
5 \\
6 \\
7 \\
8 \\
9 \\
\end{tabular}} & $\wedge$ \\
\hline Others to the Worst & Frequency & & & \\
\hline Probability & 2 & & & \\
\hline Severity & 2 & & & \\
\hline Frequency & 1 & & & \\
\hline & & & & $\checkmark$ \\
\hline \multirow{2}{*}{ Weights } & Probability & Severity & Frequency & \\
\hline & 0.3 & 0.5 & 0.2 & \\
\hline Ksi* & 0.1 & & & \\
\hline
\end{tabular}

Figure 1. Determining weights of risk parameters via BWM

\begin{tabular}{|c|c|c|c|}
\hline Probability & Description & Severity & Description \\
\hline 10 & Unavoidable & 10 & Death \\
\hline 9 & Almost assured & 9 & Permanent total inefficiency \\
\hline 8 & Frequent & 8 & Permanent serious inefficiency \\
\hline 7 & Probable & 7 & Permanent slight inefficiency \\
\hline 6 & Probability slightly higher than 0.5 & 6 & Absence from the work $>3$ weeks, return with health problems \\
\hline 5 & Probability 0.5 & 5 & Absence from the work $>3$ weeks, return after full recovery \\
\hline 4 & Probability slightly lower than 0.5 & 4 & Absence from the work $>3$ days $\&<3$ weeks, return after full recovery \\
\hline 3 & Almost improbable & 3 & Absence from the work $<3$ days, return after full recovery \\
\hline 2 & Improbable & 2 & Slight injuring without absence from the work, with full recovery \\
\hline \multirow[t]{12}{*}{1} & Impossible & 1 & No one human injury \\
\hline & Frequency & Description & \\
\hline & 10 & Permanent presence of damage & \\
\hline & 9 & Presence of damage every $30 \mathrm{~s}$ & \\
\hline & 8 & Presence of damage every $1 \mathrm{~min}$ & \\
\hline & 7 & \multirow{2}{*}{ Presence of damage every 30 mins } & \\
\hline & 6 & & \\
\hline & 5 & $\begin{array}{l}\text { Presence of damage every } 1 \mathrm{~h} \\
\text { Presence of damage every } 8 \mathrm{~h}\end{array}$ & \\
\hline & 4 & Presence of damage every 1 week & \\
\hline & 3 & Presence of damage every 1 month & \\
\hline & 2 & Presence of damage every 1 year & \\
\hline & 1 & Presence of damage every 5 years & \\
\hline
\end{tabular}

Figure 2. Scales of each risk parameter

Table 2. The aggregated decision matrix (matrix $\Lambda$ ) with added limit profiles

\begin{tabular}{ccccccccccccccccc}
\hline Risk parameter/ Hazard & $\mathrm{H} 1$ & $\mathrm{H} 2$ & $\mathrm{H} 3$ & $\mathrm{H} 4$ & $\mathrm{H} 5$ & $\mathrm{H} 6$ & $\mathrm{H} 7$ & $\mathrm{H} 8$ & $\mathrm{H} 9$ & $\mathrm{H} 10$ & $\mathrm{H} 11$ & $\mathrm{H} 12$ & $\mathrm{H} 13$ & H14 & H15 & H16 \\
\hline Probability & 7 & 8 & 9 & 6 & 8 & 8 & 4 & 4 & 7 & 7 & 7 & 7 & 7 & 7 & 9 & 9 \\
Severity & 10 & 10 & 6 & 4 & 4 & 9 & 10 & 10 & 6 & 6 & 10 & 10 & 5 & 5 & 8 & 8 \\
Frequency & 2 & 10 & 3 & 3 & 3 & 5 & 1 & 1 & 3 & 2 & 1 & 2 & 3 & 3 & 1 & 1 \\
\hline \multirow{2}{*}{ Risk parameter/ Hazard } & $\mathrm{H} 17$ & $\mathrm{H} 18$ & $\mathrm{H} 19$ & $\mathrm{H} 20$ & $\mathrm{H} 21$ & $\mathrm{H} 22$ & $\mathrm{H} 23$ & $\mathrm{H} 24$ & $\mathrm{H} 25$ & $\mathrm{H} 26$ & $\mathrm{H} 27$ & $\mathrm{H} 28$ & $l_{1}$ & $l_{2}$ & $l_{3}$ & $l_{4}$ \\
\hline Probability & 5 & 8 & 5 & 5 & 5 & 5 & 7 & 9 & 6 & 9 & 6 & 6 & 2 & 3 & 5 & 7 \\
Severity & 10 & 8 & 6 & 6 & 5 & 5 & 10 & 2 & 3 & 2 & 8 & 8 & 2 & 3 & 5 & 7 \\
Frequency & 1 & 1 & 4 & 4 & 1 & 2 & 1 & 3 & 2 & 3 & 1 & 1 & 2 & 3 & 5 & 7 \\
\hline
\end{tabular}


Table 3. The normalized decision matrix (matrix $S$ ) with added limit profiles

\begin{tabular}{|c|c|c|c|c|c|c|c|c|c|c|c|c|c|c|c|c|}
\hline Risk parameter/ Hazard & H1 & $\mathrm{H} 2$ & $\mathrm{H} 3$ & $\mathrm{H} 4$ & H5 & H6 & H7 & $\mathrm{H} 8$ & H9 & H10 & H11 & H12 & H13 & H14 & H15 & H16 \\
\hline Probability & 0.209 & 0.224 & 0.237 & 0.194 & 0.224 & 0.224 & 0.158 & 0.158 & 0.209 & 0.209 & 0.209 & 0.209 & 0.209 & 0.209 & 0.237 & 0.237 \\
\hline Severity & 0.249 & 0.249 & 0.193 & 0.157 & 0.157 & 0.236 & 0.249 & 0.249 & 0.193 & 0.193 & 0.249 & 0.249 & 0.176 & 0.176 & 0.222 & 0.222 \\
\hline Frequency & 0.240 & 0.537 & 0.294 & 0.294 & 0.294 & 0.380 & 0.170 & 0.170 & 0.294 & 0.240 & 0.170 & 0.240 & 0.294 & 0.294 & 0.170 & 0.170 \\
\hline Risk parameter/ Hazard & H17 & H18 & H19 & $\mathrm{H} 20$ & $\mathrm{H} 21$ & $\mathrm{H} 22$ & $\mathrm{H} 23$ & $\mathrm{H} 24$ & $\mathrm{H} 25$ & $\mathrm{H} 26$ & $\mathrm{H} 27$ & $\mathrm{H} 28$ & $l_{1}$ & $l_{2}$ & $l_{3}$ & $l_{4}$ \\
\hline Probability & 0.177 & 0.224 & 0.177 & 0.177 & 0.177 & 0.177 & 0.209 & 0.237 & 0.194 & 0.237 & 0.194 & 0.194 & 0.112 & 0.137 & 0.177 & 0.209 \\
\hline Severity & 0.249 & 0.222 & 0.193 & 0.193 & 0.176 & 0.176 & 0.249 & 0.111 & 0.136 & 0.111 & 0.222 & 0.222 & 0.111 & 0.136 & 0.176 & 0.208 \\
\hline Frequency & 0.170 & 0.170 & 0.340 & 0.340 & 0.170 & 0.240 & 0.170 & 0.294 & 0.240 & 0.294 & 0.170 & 0.170 & 0.240 & 0.294 & 0.380 & 0.449 \\
\hline
\end{tabular}

Table 4. The weighted normalized decision matrix (matrix $V$ ) with added limit profiles

\begin{tabular}{ccccccccccccccccc}
\hline Risk parameter/ Hazard & $\mathrm{H} 1$ & $\mathrm{H} 2$ & $\mathrm{H} 3$ & $\mathrm{H} 4$ & $\mathrm{H} 5$ & $\mathrm{H} 6$ & $\mathrm{H} 7$ & $\mathrm{H} 8$ & $\mathrm{H} 9$ & $\mathrm{H} 10$ & $\mathrm{H} 11$ & H12 & H13 & H14 & H15 & H16 \\
\hline Probability & 0.063 & 0.067 & 0.071 & 0.058 & 0.067 & 0.067 & 0.047 & 0.047 & 0.063 & 0.063 & 0.063 & 0.063 & 0.063 & 0.063 & 0.071 & 0.071 \\
Severity & 0.124 & 0.124 & 0.096 & 0.079 & 0.079 & 0.118 & 0.124 & 0.124 & 0.096 & 0.096 & 0.124 & 0.124 & 0.088 & 0.088 & 0.111 & 0.111 \\
Frequency & 0.048 & 0.107 & 0.059 & 0.059 & 0.059 & 0.076 & 0.034 & 0.034 & 0.059 & 0.048 & 0.034 & 0.048 & 0.059 & 0.059 & 0.034 & 0.034 \\
\hline Risk parameter/ Hazard & $\mathrm{H} 17$ & $\mathrm{H} 18$ & $\mathrm{H} 19$ & $\mathrm{H} 20$ & $\mathrm{H} 21$ & $\mathrm{H} 22$ & $\mathrm{H} 23$ & $\mathrm{H} 24$ & $\mathrm{H} 25$ & $\mathrm{H} 26$ & $\mathrm{H} 27$ & $\mathrm{H} 28$ & $l_{1}$ & $l_{2}$ & $l_{3}$ & $l_{4}$ \\
\hline Probability & 0.053 & 0.067 & 0.053 & 0.053 & 0.053 & 0.053 & 0.063 & 0.071 & 0.058 & 0.071 & 0.058 & 0.058 & 0.034 & 0.041 & 0.053 & 0.063 \\
Severity & 0.124 & 0.111 & 0.096 & 0.096 & 0.088 & 0.088 & 0.124 & 0.056 & 0.068 & 0.056 & 0.111 & 0.111 & 0.056 & 0.068 & 0.088 & 0.104 \\
Frequency & 0.034 & 0.034 & 0.068 & 0.068 & 0.034 & 0.048 & 0.034 & 0.059 & 0.048 & 0.059 & 0.034 & 0.034 & 0.048 & 0.059 & 0.076 & 0.090 \\
\hline
\end{tabular}

Step 7: Matrix $\Lambda$ (the aggregated decision matrix with profile values) is normalized using Eq. (1).

Step 8: Matrix $S$, which is the normalized decision matrix, is computed using Eq. (2). Table 3 provides the matrix $S$.

Step 9: Matrix $V$ which is the weighted normalized decision matrix is computed using Eq. (3). Table 4 provides the matrix $V$.

Step 10: In this case study, the positive ideal solution $A^{+}$and negative ideal solution $A^{-}$are calculated using Eqs. (4-5). The results are as follows: $A^{+}=\{0.071,0.124,0.107\} ; A^{-}=$ $\{0.034,0.056,0.034\}$.

Step $11 \&$ Step 12: In these steps, the distance of each hazard from the positive-ideal solution and the negative-ideal solution is computed using Eqs. (67) and closeness coefficient (CC) value of each hazard is determined by Eq. (8). Results of these equationsare given in Table 5 .

Step 13: Finally, we have compared $\boldsymbol{C} \boldsymbol{C}_{\boldsymbol{i}}$ with $\boldsymbol{C} \boldsymbol{C}_{\boldsymbol{j}}{ }^{\boldsymbol{p}_{u}^{k}}$ and $\boldsymbol{C} \boldsymbol{C}_{\boldsymbol{j}} \boldsymbol{p}_{l}^{\boldsymbol{k}}$ using the Eq. (9). The hazards with $\boldsymbol{C} \boldsymbol{C}_{\boldsymbol{i}}>\boldsymbol{C} \boldsymbol{C}_{\boldsymbol{j}}^{\boldsymbol{p}_{l}^{\boldsymbol{k}}}$ and $\boldsymbol{C} \boldsymbol{C}_{\boldsymbol{i}}<\boldsymbol{C} \boldsymbol{C}_{\boldsymbol{j}}^{\boldsymbol{p}_{u}^{\boldsymbol{k}}}$ are assigned to cluster $k$. In this step, all hazards are assigned to their suitable clusters. The assignments are given in Figure 3 . The clustering results will help decision makers in mitigation of the risks. They will prioritize their control measures considering the clusters (from the cluster with the highest priority to the lowest).
Assignment results show that no hazards are assigned to the "Risk" cluster, which is the lowest cluster, and only one hazard (H25) is assigned to the "Possible Risk" cluster. The vast majority of the whole hazards are assigned to the "Substantial Risk" cluster which is the middle-level cluster. There are 23 assigned hazards in this middle-level cluster. Following, H1, H6 and H12 are assigned to the "High Risk" cluster. Finally, H2 which refers to the risk regarding lack of annual periodic measurement of grounding, rechecking of electrical internal installation and panels is assigned to the most severe risk cluster "Very High Risk". For hazards and associated risks assigned to the "Very High Risk" cluster, an emergency action decision should be taken immediately. Since there is no annual periodic measurement of the grounding of the main electrical panel and fuses, it should be checked again and urgently renewed. For the hazards assigned to the "High Risk" cluster, immediate actions must be taken less than a day earlier. In the section of the facility where the extrusion process is placed, there is no machine protection equipment in case of a part ejection due to mold jamming or breakage during pressing. The surrounding area of the press should be enclosed with an unbreakable panel that protects both the press operator and other workers. The facility has not been designed according to the relevant special regulation conditions. 
Table 5. Obtained values of Dist ${ }_{i}^{+}$, Dist $_{i}^{-}$and $C C_{i}$

\begin{tabular}{lccclccc}
\hline Hazard & Dist $_{i}^{+}$ & Dist $_{i}^{-}$ & $C C_{i}$ & Hazard & Dist $_{i}^{+}$ & Dist $_{i}^{-}$ & $C C_{i}$ \\
\hline H1 & 0.060 & 0.076 & 0.559 & $\mathrm{H} 17$ & 0.076 & 0.071 & 0.486 \\
H2 & 0.004 & 0.106 & 0.963 & $\mathrm{H} 18$ & 0.075 & 0.065 & 0.465 \\
H3 & 0.056 & 0.061 & 0.520 & $\mathrm{H} 19$ & 0.052 & 0.056 & 0.522 \\
H4 & 0.068 & 0.042 & 0.381 & $\mathrm{H} 20$ & 0.052 & 0.056 & 0.522 \\
H5 & 0.067 & 0.048 & 0.416 & $\mathrm{H} 21$ & 0.084 & 0.038 & 0.310 \\
H6 & 0.032 & 0.082 & 0.718 & $\mathrm{H} 22$ & 0.072 & 0.040 & 0.359 \\
H7 & 0.077 & 0.070 & 0.476 & $\mathrm{H} 23$ & 0.074 & 0.075 & 0.503 \\
H8 & 0.077 & 0.070 & 0.476 & $\mathrm{H} 24$ & 0.084 & 0.045 & 0.349 \\
H9 & 0.057 & 0.056 & 0.497 & $\mathrm{H} 25$ & 0.083 & 0.031 & 0.272 \\
H10 & 0.066 & 0.052 & 0.440 & $\mathrm{H} 26$ & 0.084 & 0.045 & 0.349 \\
H11 & 0.074 & 0.075 & 0.503 & $\mathrm{H} 27$ & 0.076 & 0.061 & 0.445 \\
H12 & 0.060 & 0.076 & 0.559 & $\mathrm{H} 28$ & 0.076 & 0.061 & 0.445 \\
H13 & 0.061 & 0.050 & 0.450 & $l_{1}$ & 0.098 & 0.014 & 0.125 \\
H14 & 0.061 & 0.050 & 0.450 & $l_{2}$ & 0.080 & 0.029 & 0.264 \\
H15 & 0.075 & 0.067 & 0.474 & $l_{3}$ & 0.051 & 0.056 & 0.523 \\
H16 & 0.075 & 0.067 & 0.474 & $l_{4}$ & 0.028 & 0.079 & 0.739 \\
\hline
\end{tabular}

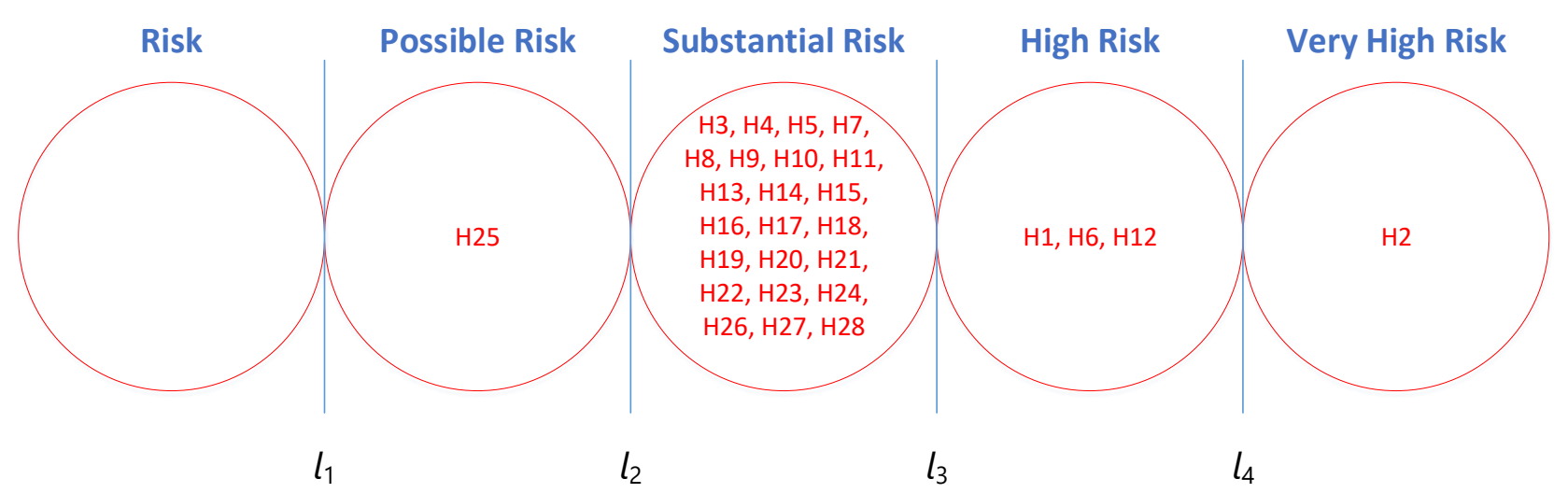

Figure 3. The assignment of hazards to the corresponding five cluster

Before the machine operator approaches the material outlet of the press and during the process of profiling by the press, it must be able to see the jamming or sticking of the profile. Since the ambient lighting is insufficient, this area should be provided with extra illumination. Besides, the press is a machine working with high noise, engineering precautions should be taken to prevent hearing loss, and the press section should be separated to reduce the intensity of the noise distributed to other parts. Similarly, it is necessary to take action in less than one month for the hazards assigned to the "Substantial Risk" cluster and earlier than one year for the hazards assigned to the "Possible Risk" cluster. No immediate action is required for hazards assigned to the "Risk" cluster, but observation must be made.

\section{CONCLUSION}

This paper presents a quantitative occupational risk assessment in the aluminum extrusion industry by a TOPSIS-Sort methodology. The main goal is to manage OHS-based risks by quantifying hazards mathematically and then clustering them in terms of $C C$ values. A case study has demonstrated at a Turkish aluminum extrusion manufacturing facility. By evaluating 28 potential hazards under the risk parameters of probability, severity and frequency, they are divided into five risk clusters named Very High Risk, High risk, Substantial risk, Possible risk, and Risk. A discussion of some control measures that allow the risks to be reduced to an acceptable level has also been carried out. Numerical results demonstrate that the most severe hazards are stemmed from the main electrical panel and fuses, 
possible negativities in the press operations of extrusion process area, the fall of material in the overhead cranes, and electrical panel hazards due to safety signs and residual current relay causes. While one hazard has been placed in the Very high risk cluster, 3 has been placed in the High risk cluster, 23 of them has been placed in the Substantial risk cluster and one has been placed in the Possible risk cluster.

The current study has some limitations from both methodology and application aspects although it presents an application of TOPSIS-Sort methodology to the OHS risk assessment domain. A limited number of OHS experts have participated in the evaluations and no priority coefficient has been used for these experts. Another limitation of the study is the sensitivity study that can be performed on how the clustering results change in case the weights of the risk parameters change.

This sorting-based methodology can be applied to OHS risk assessment problems in different industries. By injecting additional risk parameters to the methodology discussed here, or by considering a risk parameter hierarchy, the dynamic nature of risk parameters can be handled with a Bayesian network approach. For future studies, it is planned to include both the development and implementation of such a probabilistic risk assessment approach and the development and implementation of fuzzy logicbased approaches in order to better reflect the subjective judgments of the decision-making OHS expert team.

\section{CONFLICT OF INTEREST}

The Author report no conflict of interest relevant to this article

\section{RESEARCH AND PUBLICATION ETHICS STATEMENT}

The author declares that this study complies with research and publication ethics.

\section{REFERENCES}

Aneziris, O. N., Papazoglou, I. A., \& Doudakmani, O. (2010). Assessment of occupational risks in an aluminium processing industry. International journal of industrial ergonomics, 40(3), 321-329.

Behzadian, M., Otaghsara, S. K., Yazdani, M., \& Ignatius, J. (2012). A state-of the-art survey of TOPSIS applications. Expert Systems with applications, 39(17), 13051-13069.

Bi, H., Xie, X., Wang, K., Cao, Y., \& Shao, H. (2021). A risk assessment methodology of aluminum dust explosion for polishing process based on laboratory tests. Proceedings of the Institution of Mechanical Engineers, Part O: Journal of Risk and Reliability, 1748006 X20987377.

de Lima Silva, D. F., \& de Almeida Filho, A. T. (2020). Sorting with TOPSIS through boundary and characteristic profiles. Computers \& Industrial Engineering, 141, 106328.

Demir, L., Akpınar, M. E., Araz, C., \& Ilgın, M. A. (2018). A green supplier evaluation system based on a new multi-criteria sorting method: VIKORSORT. Expert Systems with Applications, 114, 479-487.

Demirci, K.M. (2013). Dünya alüminyum ticaretinde Türkiye'nin yeri. Metalurji Dergisi, 161.say1.

Sabokbar, H.F., Hosseini, A., Banaitis, A., \& Banaitiene, N. (2016). A novel sorting method TOPSIS-SORT: an applicaiton for Tehran environmental quality evaluation.

Gul, M. (2018). A review of occupational health and safety risk assessment approaches based on multi-criteria decision-making methods and their fuzzy versions. Human and ecological risk assessment: an international journal, 24(7), 1723-1760.

Gul, M., \& Guneri, A. F. (2016). A fuzzy multi criteria risk assessment based on decision matrix technique: A case study for aluminum industry. Journal of Loss Prevention in the Process Industries, 40, 89-100.

Gul, M., \& Guneri, A. F. (2018). Use of FAHP for occupational safety risk assessment: an application in the aluminum extrusion industry. Fuzzy analytic hierarchy process, 249-271.

Gul, M., Mete, S., Serin, F., \& Celik, E. (2020). FineKinney-Based Fuzzy Multi-criteria Occupational Risk Assessment: Approaches, Case Studies and Python Applications (Vol. 398). Springer Nature.

Hwang, C. L., \& Yoon, K. (1981). Methods for multiple attribute decision making. In Multiple attribute decision making (pp. 58-191). Springer, Berlin, Heidelberg.

Ishizaka, A., \& López, C. (2019). Cost-benefit AHPSort for performance analysis of offshore providers. International Journal of Production Research, 57(13), 4261-4277.

Ishizaka, A., Lolli, F., Balugani, E., Cavallieri, R., \& Gamberini, R. (2018). DEASort: Assigning items with data envelopment analysis in ABC classes. International Journal of Production Economics, 199, 7-15.

Ishizaka, A., Pearman, C., \& Nemery, P. (2012). AHPSort: an AHP-based method for sorting problems. International Journal of Production Research, 50(17), 4767-4784.

Krejčí, J., \& Ishizaka, A. (2018). FAHPSort: A fuzzy extension of the AHPSort method. International Journal of Information Technology \& Decision Making, 17(04), 1119-1145. 
Labella, Á., Ishizaka, A., \& Martínez, L. (2021). Consensual Group-AHPSort: Applying consensus to GAHPSort in sustainable development and industrial engineering. Computers \& Industrial Engineering, 152, 107013.

Marhavilas, P. K., \& Koulouriotis, D. E. (2008). A riskestimation methodological framework using quantitative assessment techniques and real accidents' data: Application in an aluminum extrusion industry. Journal of Loss Prevention in the Process Industries, 21(6), 596-603.

Qin, J., Zeng, Y., \& Zhou, Y. (2021). Context-Dependent DEASort: A Multiple Criteria Sorting Method for Ecological Risk Assessment Problems. Information Sciences.

Rezaei, J. (2015). Best-worst multi-criteria decisionmaking method. Omega, 53, 49-57.

Roy, B. (1990). The outranking approach and the foundations of ELECTRE methods. In Readings in multiple criteria decision aid (pp. 155-183). Springer, Berlin, Heidelberg.

Saaty, T. L., \& Vargas, L. G. (1984). The analytic network process. In Decision making with the analytic network process (pp. 1-40). Springer, Boston, MA.

Saaty, T. L. (1980). The analytical hierarchy process: planning, priority setting, resourceallocation. RWS Publication.

Saha, P. K. (2000). Aluminum extrusion technology. ASM International.

Sanjari, A., Saeedi, R., \& Khaloo, S. S. (2021). Semiquantitative health risk assessment of exposure to chemicals in an aluminum rolling mill. International Journal of Occupational Safety and Ergonomics, 27(2), 597-604.

Shannon, C. E. (1948). A mathematical theory of communication. The Bell system technical journal, 27(3), 379-423.

Vanderpooten, D. (1990). The construction of prescriptions in outranking methods. In Readings in multiple criteria decision aid (pp. 184-215). Springer, Berlin, Heidelberg.

Vincke, P. (1992). Exploitation of a crisp relation in a ranking problem. Theory and Decision, 32(3), 221240.

Xu, Z., Qin, J., Liu, J., \& Martinez, L. (2019). Sustainable supplier selection based on AHPSort II in interval type-2 fuzzy environment. Information Sciences, 483, 273-293.

Yamagishi, K., \& Ocampo, L. (2021). Utilizing TOPSISSort for sorting tourist sites for perceived COVID-19 exposure. Current Issues in Tourism, 1-11.

Yoon, K. P., \& Hwang, C. L. (1995). Multiple attribute decision making: an introduction. Sage publications.

Zou, Z. H., Yi, Y., \& Sun, J. N. (2006). Entropy method for determination of weight of evaluating indicators in fuzzy synthetic evaluation for water quality

\author{
assessment. Journal of Environmental \\ sciences, 18(5), 1020-1023.
}

